\title{
COMUNICAÇÃOO \\ SISTEMAS DE CONSÓRCIO MILHO FEIJÃO PARAA REGIÃO DO VALE DO RIO DOCE, MINAS GERAIS
}

\author{
Intercrop with mayze and bean at Vale do Rio Doce, Minas Gerais \\ Alexandre Sylvio Vieira da Costa ${ }^{1}$, Marcelo Barreto da Silva ${ }^{2}$
}

\begin{abstract}
RESUMO
O experimento foi conduzido no campo experimental da Univale de dezembro/98 a maio/99. Foram avaliados três sistemas consorciados de milho e feijão: fileiras duplas de milho espaçadas de $0,5 \mathrm{~m}$, com e $1,5 \mathrm{~m}$ entre as duplas, espaço ocupado com três fileiras de feijão (sistema 1); fileiras simples de milho espaçadas de $1,0 \mathrm{~m}$ com uma fileira intercalar de feijão (sistema 2) e fileiras simples de milho espaçadas de $1,0 \mathrm{~m}$ com duas fileiras intercalares de feijão (sistema 3 ), além dos plantios solteiros. O milho utilizado foi o híbrido AG1051 e o feijão, a cultivar Carioca CI257. As culturas foram semeadas simultaneamente e todos os sulcos adubados. Foram avaliados no feijão os componentes da produção e a produtividade; no milho, a produção de massa verde para silagem e a produtividade. No sistema consorciado, o número de vagens por planta de feijão sofreu redução significativa em relação ao plantio solteiro, sendo o fator que mais contribuiu para queda da produtividade, enquanto os demais componentes, número de sementes por vagem e peso de 100 sementes, não diferiram do plantio solteiro. No milho, o plantio em fileiras duplas reduziu significativamente a sua produtividade. O sistema 3 apresentou maior índice de equivalência de área quando se considerou a produção de grãos e a produção de milho silagem.
\end{abstract}

Termos para indexação: Culturas intercalares, Zea mays, Phaseolus vulgaris.

\section{ABSTRACT}

The experiment was accomplished in the experimental field of Univale from december/1998 to may/1999. Three systems comprising mayze intercrop with bean were assessed: Double-spaced rows of mayze $0,5 \mathrm{~m}$ and 1,5 m between couples with three bean rows (system 1); simple-spaced rows of mayze 1,0 $\mathrm{m}$ with a row of bean in the middle (system 2); simple rows of mayze 1,0 $\mathrm{m}$ with two rows of bean in the middle (system 3); as well as single crops. The mayze utilized was the hybrid AG1051 and the bean was Carioca CI257. Both species were sowed simultaneously and fertilized. Bean yield component factors and productivity were assessed. As for production of green mass for silage and productivity were assessed as well. In the intercrop system, the pod number per plant suffered a significant reduction in relation to the single crop. Such factor was the most important to productivity decreased. The components seed per pod number and seed weight showed no difference from single plantation. In mayze, the doubled-row sowing significantly reduced productivity. Intercrop system 3 presented higher index of area equivalency when grain and mayze silage production was concenrned.

Index terms: Intercrop, Zea mays, Phaseolus vulgaris.

(Recebido em 8 de novembro de 2006 e aprovado em 10 de julho de 2007)

O plantio do feijão em consórcio com outras culturas é procedimento comum no Brasil, sendo realizado principalmente por pequenos agricultores. Em Minas Gerais, estima-se que $65 \%$ do feijão das águas e $50 \%$ do feijão da seca estejam associados com milho e outras culturas. Nesses cultivos ocorre competição por luz, nutrientes, água e outros fatores envolvidos no crescimento e produção das culturas. A competição depende das espécies envolvidas, dos seus sistemas radiculares e da disponibilidade de água, nutrientes e oxigênio.

Vários resultados de pesquisa têm sido obtidos com o consórcio milho-feijão, abrangendo diversos aspectos como o sistema e épocas de semeadura, porte das plantas, espaçamento, população de plantas, adubação, retorno econômico e outros, que têm permitido aumentar a eficiência do sistema (VIEIRA, 1985).

Araújo et al. (1986), analisando os componentes de produção do feijão em vários sistemas de cultivo, observaram que a redução na produção de grãos nos sistemas de consórcio intercalar e intercalar de substituição com o milho ocorreu por causa de um menor número de vagens por planta. Lana et al. (2003) citam que o número de vagens por planta é o caráter com maior potencial a ser utilizado na seleção da variedade de feijão em monocultivo, visando à semeadura no consórcio.

'Doutor em Fitotecnia, Professor - Faculdade de Ciências Agrárias - Laboratório de Solos - Universidade Vale do Rio Doce/UNIVALE - Campus II, Rua Israel Pinheiro 2000 - Universitário - 35020-220 - Governador Valadares, MG - asylvio@univale.br

2Doutor em Fitopatologia, Professor - Faculdade de Ciências Agrárias - Laboratório de Solos - Universidade Vale do Rio Doce/UNIVALE - Campus II Rua Israel Pinheiro 2000 - Universitário - 35020-220 - Governador Valadares, MG - mbarreto@univale.br 
As leguminosas possuem elevado teor de $\mathrm{N}$ e podem beneficiar a cultura do milho. A decomposição dos nódulos também disponibiliza nitrogênio para o milho no consórcio (BONETTI, 1991). Senaratine et al. (1995) afirmam que essa capacidade de disponibilização de nitrogênio no solo pelas leguminosas, entretanto, é bastante variável entre cultivares.

Resultados mostram que os rendimentos de feijão no consórcio são menores que no monocultivo (CRUZ et al., 1987). Ramalho et al. (1984) avaliaram o consórcio de nove cultivares de feijão com cultivares de milho em diferentes sistemas e observaram redução média de $58 \%$ na produtividade do feijão consorciado, quando comparada ao monocultivo. Candal Neto et al. (1986) observaram reduções que oscilaram de 37 a $50 \%$ em relação ao monocultivo. Outros trabalhos demonstram que o rendimento do feijão consorciado é igual ou até mesmo superior ao do monocultivo (FONTANA NETTO et al., 1984).

No Brasil, em razão da grande importância que o consórcio representa, tem-se procurado estabelecer sistemas de produção milho-feijão mais adaptados para as diversas regiões. Esses sistemas, no entanto, são recomendados com base na experiência de agricultores e extensionistas e, em parte, nos resultados da pesquisa, resultando em recomendações específicas para diversas regiões do país (EMBRAPA, 1977).

Objetivou-se, com este trabalho, verificar o desenvolvimento e a produtividade das culturas do milho e do feijão no sistema consorciado, em diferentes arranjos espaciais.

A pesquisa foi conduzida no campo experimental da Universidade Vale do Rio Doce (UNIVALE), Campus II, localizado no município de Governador Valadares-MG, no período de dezembro de 1998 a maio de 1999, no denominado cultivo de primavera-verão (VIEIRA \& VIEIRA, 1995). O solo da área experimental foi classificado como Argissolo vermelho amarelo. A adubação foi realizada em função do resultado da análise de solo e foi equivalente a $25 \mathrm{~g}$ de fertilizante formulado 8-28-16 por metro de sulco, na cultura do milho. A mesma adubação foi realizada nas linhas da cultura do feijão. Foram avaliados três sistemas de manejo: fileiras duplas de milho espaçadas de $0,5 \mathrm{~m}$, com e $1,5 \mathrm{~m}$ entre as duplas, espaço ocupado com três fileiras de feijão (sistema 1); fileiras simples de milho espaçadas de 1,0 m com uma fileira intercalar de feijão (sistema 2); fileiras simples de milho espaçadas de 1,0 m com duas fileiras intercalares de feijão (sistema 3), além dos plantios solteiros. A densidade de semeadura adotada foi de 5 plantas. $\mathrm{m}^{-1}$ para o milho e 10 plantas. $\mathrm{m}^{-1}$ para o feijão, obtidas por meio de desbaste após a emergência das plantas. As parcelas experimentais foram de $5 \mathrm{~m}$ x $4 \mathrm{~m}$. Os sulcos foram abertos manualmente com $5 \mathrm{~cm}$ de profundidade. $\mathrm{O}$ delineamento experimental foi blocos ao acaso com três repetições. O milho utilizado foi o híbrido AG 5011 e o feijão a cultivar CI 257, do tipo carioca. Durante o desenvolvimento das culturas foi realizada uma aplicação de Decis na cultura do milho para controle da lagarta do cartucho. Não foi realizado qualquer controle químico na cultura do feijão. Aos 20 dias após a semeadura foi realizada uma capina manual e aos 30 dias realizou-se uma adubação de cobertura com nitrogênio na forma de uréia (40 kg.ha-1 de N), na cultura do milho, tanto solteiro como consorciado. Por ocasião da colheita do feijão foram coletados, por parcela, doze m lineares no sistema 1 , quatro $\mathrm{m}$ lineares no sistema 2 , oito $\mathrm{m}$ lineares no sistema 3 e seis $m$ lineares no cultivo solteiro, na região central da parcela, descartando-se 1,0 $\mathrm{m}$ da extremidade de cada parcela. Na colheita do milho grão foi considerada a mesma parcela útil utilizada para o feijão e para o milho silagem, sendo coletados $2 \mathrm{~m}$ lineares dentro da parcela útil, aos 80 dias após o plantio, cortando-se as plantas na região do colo e pesando-as para determinação da massa da matéria fresca. A coleta dos grãos de milho ocorreu quando as plantas e as espigas encontravam-se secas. Na cultura do feijão foram avaliados: número de plantas, peso de 100 sementes, número de vagens por planta, o número de grãos por vagem e a produtividade de grãos. Na cultura do milho avaliou-se a produção de massa verde para silagem e a produção de grãos. Outros fatores avaliados foram o Índice de Equivalência de Área (IEA), que compara as produções em sistemas consorciados com plantio solteiro e a rentabilidade bruta dos sistemas. O IEA foi calculado considerando-se a produção de grãos de milho (IEA 1) e a produção da massa verde de milho (IEA 2).

$$
\text { IEA }=\frac{\text { Prod. do feijão consorciado }}{\text { Prod. feijão solteiro }}+\frac{\text { Prod. do milho consorciado }}{\text { Prod. milho solteiro }}
$$

O número final de plantas em 10 metros lineares, como era esperado, não interferiu entre os tratamentos (Tabela 1). A população de plantas do feijão nos sistemas consorciados 1 e 3 apresentaram índices de 84,3\% e 83,4\% em relação ao sistema solteiro. A população que mais se aproximou do cultivo solteiro foi a do sistema 2 com 96,2\%. Costa (1997), em trabalho de campo com 20 cultivares de feijão, observou que sementes de milho germinando 
próximo às sementes de feijão não interferem na germinação da leguminosa, indicando não estar envolvido qualquer tipo de ação alelopática.

Quando se considerou o número de plantas por hectare, houve diferenças, pois o total de linhas de plantio de feijão foi diferenciado entre os sistemas. O plantio solteiro não diferiu do sistema 3, pois ambos teriam, teoricamente, 20 mil metros de linha de feijão por hectare. Os sistemas 1 e 2, entretanto, com populações teoricamente de 15 e 10 mil metros lineares de feijão por hectare, respectivamente, mostram-se inferiores (Tabela 1).

Ainda na Tabela 1, observa-se que as plantas de feijão cultivadas no sistema solteiro desenvolveram aproximadamente o dobro do número de vagens por planta quando comparado às dos consórcios, evidenciando que a cultura do milho interferiu na produção de frutos pela leguminosa. Tomando-se o número de vagens por hectare, os resultados (Tabela 1) também mostraram superioridade do cultivo exclusivo de feijão. No período das águas, Costa (1997) observou resultados diferentes: as plantas de feijão desenvolveram o mesmo número de vagens nos sistemas solteiro e consorciado. No presente trabalho, a redução deveu-se, provavelmente, a não adaptação da cultivar de feijoeiro ao sistema consorciado.

A avaliação do número de grãos por vagem não evidenciou diferenças significativas entre os tratamentos. Esse mesmo resultado foi obtido por Costa (1997) avaliando cultivares de feijão em consórcio e solteiro, onde os valores foram semelhantes entre os sistemas, principalmente no período das águas.

Quanto ao peso de 100 grãos (Tabela 2), não ocorreram diferenças significativas entre os tratamentos, indicando que os diferentes sistemas de cultivo não alteraram o processo fisiológico de formação das sementes, mantendo as características morfológicas e de massa do grão da cultivar. Esse resultado, juntamente com o número de grãos por vagem, demonstra que o principal fator de produção, que interfere na produtividade das plantas de feijão em sistemas consorciados, é o número de vagens por planta, como citado por Araújo et al. (1986).

Apesar de se tratar de plantas C3, com saturação a reduzidos valores de radiação luminosa, os feijoeiros ficam prejudicados quando cultivados sob plantas de milho, porque elas absorvem os principais comprimentos de onda responsáveis pela fotossíntese, permitindo a passagem de uma quantidade muito pequena de comprimentos de onda fotossínteticamente ativos. Portes \& Silva (1996) verificaram que, em milharal com fileiras espaçadas de um metro no máximo de desenvolvimento, apenas $45 \%$ da radiação fotossinteticamente ativa atingia o topo das plantas de feijão.

Os resultados obtidos com os componentes refletiram-se na produtividade do feijão (Tabela 2). Não ocorreram diferenças significativas entre os sistemas consorciados, de forma semelhante ao obtido por outros autores como Reis et al. (1985). O sistema 3 apresentou produtividade $71,2 \%$ inferior à do cultivo solteiro, apesar da quantidade semelhante de linhas de feijão semeadas por hectare (20 mil metros), produzindo apenas 362,9 quilos, resultados também observados por Candal Neto \& Vieira (1994). Segundo Vieira (1999), a quebra de produção do feijão consorciado em relação ao solteiro varia entre 20 e $70 \%$, dependendo da densidade populacional das culturas. Entre os sistemas de cultivo consorciado, novamente o sistema 1 apresentou tendência de maior produtividade, mesmo com número menor de linhas de plantio de feijão. Esses resultados também foram obtidos por Raposo et al. (1995) que observaram maior produção da cultura do feijão no sistema de consórcio com fila dupla de milho e tripla de feijão. Diferente dos resultados obtidos nesse trabalho, Pereira Filho et al. (2000) observaram que a produtividade do feijão semeado entre as fileiras duplas do milho foi inferior quando comparado ao sistema com fileiras simples.

Tabela 1 - Características agronômicas do feijoeiro cv. CI257 em cultivo solteiro e em diferentes sistemas de consórcio com o milho. Governador Valadares-MG, 1998/99.

\begin{tabular}{lcccccc}
\hline Sistema & $\begin{array}{c}\mathrm{N}^{0} \text { de plantas/ } \\
\text { hectare }\left(\mathrm{x} 10^{3}\right)\end{array}$ & $\begin{array}{c}\text { \%em relação } \\
\text { ao solteiro }\end{array}$ & $\begin{array}{c}\mathrm{N}^{\mathrm{o}} \text { de vagens/ } \\
\text { planta }\end{array}$ & $\begin{array}{c}\text { \% em relação } \\
\text { ao solteiro }\end{array}$ & $\begin{array}{c}\mathrm{N}^{\mathrm{o}} \text { de grãos/ } \\
\text { vagem }\end{array}$ & $\begin{array}{c}\text { \%em relação } \\
\text { ao solteiro }\end{array}$ \\
\hline Sistema 1 & $145,0 \mathrm{BC}$ & 63,3 & $4,15 \mathrm{~B}$ & 47,0 & $4,84 \mathrm{~A}$ & 100,0 \\
Sistema 2 & $110,3 \mathrm{C}$ & 48,2 & $4,43 \mathrm{~B}$ & 50,1 & $3,32 \mathrm{~A}$ & 68,6 \\
Sistema 3 & $191,3 \mathrm{AB}$ & 83,6 & $4,03 \mathrm{~B}$ & 45,6 & $3,04 \mathrm{~A}$ & 62,8 \\
Solteiro & $228,9 \mathrm{~A}$ & 100,0 & $8,84 \mathrm{~A}$ & 100,0 & $4,84 \mathrm{~A}$ & 100,0 \\
\hline $\mathrm{CV}(\%)$ & 15,37 & & 11,84 & 42,44 & \\
\hline
\end{tabular}

*Em cada coluna, médias seguidas de mesma letra não diferem pelo teste de Tukey a 5\% de probabilidade. 
Com relação à produção de matéria verde para silagem (Tabela 3), observa-se, a despeito de não haver diferenças significativas, uma tendência do sistema 1 prejudicar o desenvolvimento das plantas de milho, produzindo $78,7 \%$ da matéria verde produzida no plantio solteiro. Na produtividade de grãos foram observadas diferenças significativas entre os sistemas, sendo que o sistema 1 apresentou resultados inferiores aos sistemas 3 e solteiro. A produtividade do sistema 1 foi aproximadamente $39 \%$ menor que a do milho solteiro e $45 \%$ menor que a do sistema 3 . A simples mudança de disposição das linhas de milho no sistema de linhas duplas alterou o desenvolvimento do milho, apesar de ter ocorrido um pequeno benefício na produtividade das plantas de feijão nesse sistema. Nos demais sistemas, o consórcio com feijão não prejudicou o desenvolvimento do milho. Esse resultado também foi observado por Raposo et al. (1995), onde o arranjo com duas linhas de milho e três de feijão promoveu redução na produtividade do milho e aumento na produção de feijão. A manutenção da produção do milho em sistemas consorciados com feijão, comparado ao monocultivo, foi observado por Silva et al. (1996), onde a semeadura de feijão na linha do milho e na entrelinha não interferiu fisiologicamente no desenvolvimento da gramínea. Pereira Filho et al. (2000), por outro lado, verificaram que o milho semeado em fileira dupla, em consórcio com feijão, não apresentou redução na sua produtividade em relação ao cultivo em fileiras simples.

O rendimento da cultura do feijão no consórcio representou apenas $20-30 \%$ do rendimento da cultura exclusiva;

O número de vagens por planta foi o principal componente do rendimento na definição da produtividade da cultura do feijão;

A produtividade do milho (grão e silagem) em consórcio foi afetada pela distribuição espacial das plantas da gramínea na área e não pela presença do feijoeiro.

Tabela 2 - Avaliação dos fatores de produção do feijoeiro cv. CI 257 em cultivo solteiro e em diferentes sistemas de consórcio com o milho. Governador Valadares-MG, 1998/99.

\begin{tabular}{lcccc}
\hline Sistemas & $\begin{array}{c}\text { Peso de 100 } \\
\text { sementes (gramas) }\end{array}$ & $\begin{array}{c}\text { \%em relação } \\
\text { ao solteiro }\end{array}$ & $\begin{array}{c}\text { Produtividade } \\
(\mathrm{kg} / \mathrm{ha})\end{array}$ & $\begin{array}{c}\text { \%em relação } \\
\text { ao solteiro }\end{array}$ \\
\hline Sistema 1 & $15,91 \mathrm{~A}$ & 91,3 & $410,4 \mathrm{~B}$ & 32,6 \\
Sistema 2 & $15,67 \mathrm{~A}$ & 90,0 & $254,7 \mathrm{~B}$ & 20,3 \\
Sistema 3 & $15,32 \mathrm{~A}$ & 87,9 & $362,9 \mathrm{~B}$ & 28,8 \\
Solteiro & $17,43 \mathrm{~A}$ & 100,0 & $1257,5 \mathrm{~A}$ & 100,0 \\
\hline CV $(\%)$ & 14,04 & & 33,41 &
\end{tabular}

*Em cada coluna, médias seguidas de mesma letra não diferem pelo teste de Tukey, a 5\% de probabilidade.

Tabela 3 - Avaliação da produtividade da matéria verde para silagem e de grãos do milho cultivado em diferentes sistemas de consórcio com o feijão cv. CI 257. Governador Valadares - MG, 1998/99.

\begin{tabular}{lcccc}
\hline Sistemas & $\begin{array}{c}\text { Matéria Verde } \\
\text { (ton/ha) }\end{array}$ & $\begin{array}{c}\text { \% em relação } \\
\text { ao solteiro }\end{array}$ & $\begin{array}{c}\text { Produtividade } \\
\text { de grãos (kg/ha) }\end{array}$ & $\begin{array}{c}\% \text { em relação } \\
\text { ao solteiro }\end{array}$ \\
\hline Sistema 1 & $38,85 \mathrm{~A}$ & 78,7 & $3833,3 \mathrm{~B}$ & 61,3 \\
Sistema 2 & $50,82 \mathrm{~A}$ & 103,0 & $5916,7 \mathrm{AB}$ & 94,7 \\
Sistema 3 & $50,03 \mathrm{~A}$ & 101,4 & $6625,0 \mathrm{~A}$ & 106,0 \\
Solteiro & $49,35 \mathrm{~A}$ & 100,0 & $6250,0 \mathrm{~A}$ & 100,0 \\
\hline CV $(\%)$ & 16,96 & & 16,61 &
\end{tabular}

*Médias seguidas de mesma letra não diferem pelo teste de Tukey, a 5\% de probabilidade. 


\section{REFERÊNCIAS BIBLIOGRÁFICAS}

ARAÚJO, G. A. A.; FONTES, L. A. N.; LOPES, N. F. Produção e componentes da produção em sistemas de cultivos associados e exclusivos de milho e feijão. Revista Ceres, Viçosa, v. 33, n. 190, p. 469-478, 1986.

BONETTI, R. Transferência de nitrogênio do feijão para o milho consorciado: avaliação pelo método de diluição isotópica do ${ }^{15} \mathrm{~N}$ e efeito da associação micorrízica. 1991. $63 \mathrm{f}$. Tese (Doutorado em Agronomia) - Escola Superior de Agricultura Luiz de Queiroz, Piracicaba, 1991.

CANDAL NETO, J. F.; PACOVA, B. E. V.; GUIDONO, A. L. Comportamento de cultivares de feijão em cultivo exclusivo e associado ao milho no Espírito Santo. Pesquisa Agropecuária Brasileira, Brasília, v. 21, p. 1155-1159, 1986.

CANDAL NETO, J. F.; VIEIRA, R. F. Comportamento de cultivares de feijão (Phaseolus vulgaris L.) em consórcio com o milho (Zea mays) na região serrana do Espírito Santo. Revista Ceres, Viçosa, v. 41, p. 168-177, 1994.

COSTA, A. S. V. da. Comportamento de variedades de feijão (Phaseolus vulgaris L.) em dez ambientes compreendendo cinco sistemas de produção. 1997. 51 f. Tese (Doutorado em Fitotecnia) - Universidade Federal de Viçosa, Viçosa, 1997.

CRUZ, J. C.; RAMALHO, M. A. P.; SALES, L. T. G. Utilização de cultivares de milho prolífico no consórcio milho-feijão. Pesquisa Agropecuária Brasileira, Brasília, v. 22, n. 2, p. 203-211, 1987.

EMPRESA BRASILEIRA DE PESQUISA AGROPECUÁRIA. Sistemas de produção para milho e feijão. Curitiba: ACARPA, 1977. 65 p. (Boletim, 23).

FONTANA NETTO, F.; VIEIRA, C.; CARDOSO, A. A. Cultura associada de feijão e milho: VIII. efeitos da altura e da população de plantas de milho. Revista Ceres, Viçosa, v. 31, n. 178, p. 489-501, 1984.

LANA, A. M. Q.; CARDOSO, A. A.; CRUZ, C. D. Herdabilidades e correlaçõesentre caracteres de linhagens de feijão obtidas em monocultivo e em consórcio com o milho. Ciência Rural, Santa Maria, v. 33, n. 6, p. 25-36, 2003.
PEREIRA FILHO, I. A. P.; OLIVEIRA, A. C. de; CRUZ, J. C. Sistema de plantio de milho em fileiras duplas e simples em consórcio com feijoeiro comum. Pesquisa Agropecuária Brasileira, Brasília, v. 35, n. 5, p. 234-245, 2000.

PORTES, T. da A.; SILVA, C. C. da. Cultivo consorciado. In: ARAÚJO, R. S. Cultura do feijão comum no Brasil. Piracicaba. Potáfos, 1996. p. 619-638.

RAMALHO, M. A. P.; SILVA, A. F.; AIDAR, H. Cultivares de milho e feijão em monocultivo e em dois sistemas de consorciação. Pesquisa Agropecuária Brasileira, Brasília, v. 19 , n. 7 , p. $827-833,1984$

RAPOSO, J. A. de A.; SCHUCH, L. O. B.; ASSIS, F. N. de; MACHADO, A. A. Consórcio de milho e feijão em diferentes arranjos e populações de plantas em Pelotas, RS. Pesquisa Agropecuária Brasileira, Brasília, v. 30, p. 639-647, 1995.

REIS, W. P.; RAMALHO, M. A. P.; CRUZ, J. C. Arranjos e populações do feijoeiro na consorciação com o milho. Pesquisa Agropecuária Brasileira, Brasília, v. 20, n. 5, p. 575-584, 1985.

SENARATINE, R.; LIYANAGE, N. D. L.; SOPER, R. J. Nitrogen fixation and $\mathrm{N}$ transfer from Cowpea, mungbean and groundnut when intercropped with maize. Fertilizer Research, Dordrecht, v. 40, p. 41-48, 1995.

SILVA, M. V. da; ANDRADE, M. J. B. da; DURA, M. R.; TEIXEIRA, I. R.; LUNKES, J. A. Comportamento do milho de pipoca em monocultivo e em consórcio com o feijoeiro comum. In: REUNIÃO NACIONAL DE PESQUISA DE FEIJÃO, 5., 1996, Goiânia. Anais... Goiânia: EmbrapaCNPAF, 1996. p. 415-417.

VIEIRA, C. Estudo monográfico do consórcio milho-feijão no Brasil. Viçosa: UFV, 1999. 183 p.

VIEIRA, C. $O$ feijão em cultivos consorciados. Viçosa: UFV, 1985. $134 \mathrm{p}$.

VIEIRA, C.; VIEIRA, R. F. Épocas de plantio do feijão e proposta de nomenclatura para designá-las. Revista Ceres, Viçosa, v. 42, p. 685-688, 1995. 